\title{
Os estilos de liderança na gestão dos serviços bancários.
}

\section{Resumo}

O presente artigo é resultado de uma pesquisa realizada com os gestores de agências bancárias localizadas no Rio Grande do Sul. Buscou-se a identificação do estilo de liderança que eles mais utilizam, segundo a sua própria visão, observando variantes como o tamanho das agências, a quantidade de funcionários subordinados, a região de localização e o atingimento das metas propostas. Após uma revisão bibliográfica que considerou os Sistemas de Administração de Likert, foram analisadas as incidências percentuais e seu significado real prático, confirmando as teorias apresentadas no que tange à forma de obtenção de melhores resultados gerenciais.

Palavras-chave: liderança; sistemas de administração; gestão de serviços.

\section{Styles of leadership in management of banking services.}

\section{Abstract}

This article is the result of a survey conducted with managers of bank branches located in Rio Grande do Sul was sought to identify the leadership style they use most, according to his own vision, noting variations to the size of the agencies, the number of employees who report, the region of location and achievement of goals. After a literature review found that the Management Systems Likert analyzed the percentage impact and meaning practical real, confirming the theories presented in regard to how to achieve better business results.

Keywords: leadership; Management Systems, management services.

\footnotetext{
1 Mestre em Administração pela Universidade do Vale do Rio dos Sinos (UNISINOS) em 2014, Especialista em Gestão Estratégica de Pessoas pelo Centro Universitário UNIVATES em 2010 e Bacharel em Administração pela Universidade de Passo Fundo (UPF) em 2005. Atualmente Professor da Universidade do Vale do Rio dos Sinos (UNISINOS) e da Faculdade Luterana São Marcos (FLSM). email: danielauler@hotmail.com.br
} 


\section{Introd ução}

A sociedade empresarial surgida a partir dos artesãos feudais, ampliada pela Revolução Industrial e aprimorada pela Revolução Tecnológica, reflete, neste início de terceiro milênio, os principais ideais e valores surgidos a partir da Revolução Francesa. A ascensão da burguesia trouxe à humanidade valores que formaram a base do capitalismo, sistema econômico que domina o mundo contemporâneo. Nesse sentido, as organizações, da mesma forma que as pessoas, buscam o acúmulo de capitais resultantes da obtenção de lucros reais gerados através da administração dos variados recursos disponíveis, independentemente do ambiente onde estão inseridas. Dentre os mais diversos ramos de atuação destas organizações, destaca-se o de serviços, mais especificamente o de intermediação financeira, que atua no sentido de aproximar tomadores e fornecedores de recursos, obtendo-os de onde estiverem abundantes para levá-los até onde forem escassos. Um dos aspectos que chama a atenção neste tipo de empresa é o modo como aloca seus recursos humanos e especialmente a gestão destes frente aos demais, uma vez que se trata de serviço, e como tal, o colaborador é parte integrante do produto final entregue ao consumidor. Nesse sentido, o estilo de liderança adotado pelo primeiro gestor de cada filial da empresa exerce grande influência no produto final apresentado. Sendo assim, o presente artigo busca discutir a questão:

Qual o estilo de liderança mais utilizado pelos primeiros gestores das agências bancárias localizadas no Estado do Rio Grande do Sul?

O presente estudo foi desenvolvido com os primeiros gestores das agências de um grande banco nacional, localizadas no Estado do Rio Grande do Sul, buscando identificar a visão que cada um tem sobre seu estilo de liderar os demais membros da filial pela qual respondem. Logo mais, os resultados, no que tange aos estilos de liderança adotados, foram divididos levando em conta as seguintes variáveis: tamanho de agência, região de localização, quantidade de funcionários subordinados e resultado obtido nos respectivos acordos de trabalho do primeiro semestre de 2009.

O estudo se justifica pela necessidade urgente de rápida adaptação dos gestores de serviços, especialmente os bancários, uma vez que relacionando as variáveis acima citadas, poderá ser sugerido um estilo de liderança a ser utilizado para cada característica da equipe a ser gerenciada. Na dinâmica do mundo contemporâneo quanto menos tempo for utilizado com a adaptabilidade, mais rápido os objetivos propostos serão atingidos.

Assim, o presente artigo expõe os resultados percentuais encontrados, buscando separálos nas variáveis citadas a fim de que possa ser sugerido um norte aos administradores de serviços, em especial, aqueles que se dedicam aos de intermediação financeira.

\section{A liderança e seus conceitos básicos}

Este capítulo busca detalhar a essência do conceito de liderança, além de apresentar as teorias nas quais o presente estudo está baseado e, assim, trazer um melhor entendimento acerca do assunto debatido.

Liderança é atualmente um dos temas mais discutidos no mundo empresarial, tanto em nível teórico quanto em nível organizacional. Em sua essência, a palavra liderar vem do latim läden, que significa ir ou viajar junto, sentido que por si só já explica, resumidamente, o conceito que ora se apresenta. De uma forma muito mais completa, Chiavenato(2002) conceitua liderança como uma influência interpessoal exercida em dada situação e dirigida pelo processo de comunicação humana para a consecução de um ou mais objetivos específicos. A partir desse conceito aparecem diversos aspectos da liderança em si. O primeiro deles trata da influência, que nada mais é do que uma transação interpessoal, na qual uma pessoa age no sentido de modificar ou provocar o comportamento de outra, de maneira intencional (Chiavenato 2002), 
ou seja, é a força que leva os líderes a fazer com que as pessoas façam aquilo que eles querem que seja feito. Em conseqüência, surgem os aspectos de poder e autoridade. O primeiro está relacionado com a força que as pessoas realmente têm, a influência que exercem sobre as outras, de uma maneira informal, pois não há como se determinar que alguém tenha poder ou não, ele é uma questão de aceitação daqueles que são influenciados. Já a autoridade é o poder legitimado, formalmente designado a alguém em razão das circunstâncias e características situacionais envolvidas na organização, totalmente ligado ao papel que este indivíduo exerce no grupo social.

Um outro aspecto relevante é que a liderança está ligada diretamente a determinada situação. Toda esta influência anteriormente comentada só poderá existir frente às situações enfrentadas pelo grupo social onde estão ocorrendo. Pode-se afirmar que o grupo somente irá aceitar a liderança exercida se lhe convier, se for uma forma satisfatória de se chegar a determinado objetivo. Diante disso, um mesmo grupo social pode, dependendo da situação em que estiver envolvido, adotar estilos de liderança, ou mesmo líderes distintos conforme o que Ihe convier. Outro aspecto está ligado à forma de comunicação adotada pelo líder. Surge aqui a verdadeira arte da liderança, pois através das mais variadas formas de comunicação o líder realmente irá exercer a sua influência sobre o grupo social onde estiver inserido. Cabe salientar que comunicar não é um processo nada fácil. Muitas organizações dedicam horas e horas nas melhorias deste processo e ainda assim enfrentam graves problemas, mesmo com a enorme gama de meios à disposição atualmente.

Uma última característica, enfim, está no fato de que a liderança só é exercida quando existe um objetivo a ser cumprido. Os grupos sociais de uma forma geral existem para alcançar determinada meta e esta é a razão final para a qual a liderança está constituída: chegar a um resultado. O líder, então, surge como um meio, um facilitador, um motivador, um balizador, um instrumento adotado pelo grupo social a fim de que sejam atingidos os objetivos finais para os quais o próprio grupo se propôs. Concluindo, Chiavenato(2002) expõe muito bem que, para ser bem sucedido como líder, o gerente deve saber lidar com os aspectos relativos à motivação, à comunicação, às relações interpessoais, ao trabalho em equipe e à dinâmica de grupos.

Nesse sentido, as teorias sobre liderança são divididas em três grupos, muito bem expostos por Bergamini(1994):

- teorias dos traços de personalidade: estudos iniciais que relacionam as características de personalidade do líder, suas qualidades pessoais, consideradas pelos autores as principais facilitadoras no desempenho do papel da liderança. Cabe ressaltar que este grupo de estudiosos entendia os líderes como seres diferentes dos demais por possuírem alguns traços de personalidade capazes de emergi-los no comando e, até mesmo, mantê-los em suas posições, sob qualquer hipótese;

- teorias sobre os estilos de liderança: descrevem as maneiras e estilos de comportamento adotados pelos líderes, buscando características relacionadas as dinâmicas por eles adotadas, atendo-se àquilo que fazem, especificando os tipos de comportamento que se mostram mais eficazes na direção de seus seguidores;

- enfoques situacionais: discorrem sobre como adequar o comportamento dos líderes e liderados às diversas situações enfrentadas, considerando aspectos do ambiente dentro do qual o líder esteja agindo.

Este artigo considera as teorias sobre os estilos de liderança, destacando o trabalho desenvolvido por Rensis Likert, expoente da Teoria Comportamental. Os autores reunidos neste grupo acreditam que a administração é diferente em todas as organizações, variando 
sempre em função de fatores internos e externos, jamais existindo um padrão que possa ser seguido por todas elas. Likert, então, propôs quatro diferentes perfis organizacionais que ficaram conhecidos como Sistemas de Administração de Likert. A partir de Likert(1975), Likert(1979), Likert e Likert(1979) e Chiavenato(1999), pode-se realizar a descrição destes sistemas tomando-se por base quatro variáveis:

Processo decisorial: define como são tomadas as decisões na empresa e quem as toma, sua centralização ou descentralização, concentração no topo da hierarquia ou dispersão;

Sistemas de comunicação: define como as comunicações gerais são transmitidas e recebidas dentro da organização, se o fluxo de informações é vertical e descendente, vertical com dupla mão de direção ou horizontal;

Relacionamento interpessoal: define como as pessoas se relacionam entre si na organização e qual o grau de liberdade nesse relacionamento humano, se trabalham isoladas entre si ou em equipe;

Sistema de recompensas e punições: define como a empresa motiva as pessoas a se comportarem de certa maneira e se essa motivação é positiva e incentivadora ou restritiva e inibidora.

\section{Seguem abaixo os quatro Sistemas de Administração de Likert:}

- Sistema I - Autoritário Coercitivo: é um sistema autocrático e forte, coercitivo e fortemente arbitrário, que controla rigidamente tudo o que ocorre na organização. É o sistema mais duro e fechado. Suas principais características são:

Processo decisorial: totalmente centralizado na cúpula da organização. Todas as ocorrências imprevistas e não rotineiras devem ser levadas à cúpula para a resolução e todos os eventos devem ser exclusivamente decididos pela cúpula empresarial. Nesse sentido o nível institucional torna-se sobrecarregado com a tarefa decisorial.

Sistema de comunicações: é um sistema precário e emperrado. As comunicações ocorrem sempre verticalmente, no sentido descendente, carregando exclusivamente ordens e raramente orientações ou explicações. Não existem comunicações laterais. As pessoas não são solicitadas a gerar informações, o que faz as decisões tomadas na cúpula se alicerçarem em informações limitadas, incompletas ou errôneas.

Relacionamento interpessoal: considerado prejudicial ao bom andamento dos trabalhos. Conversas informais são vistas com desconfiança e evitadas ao máximo. A organização informal é vedada. Cargos e tarefas são organizados para isolar as pessoas.

Sistema de recompensas e punições: destaque para as punições e para as medidas disciplinares, criando um ambiente de temor e desconfiança. Todos precisam cumprir fielmente as regras e os regulamentos internos e dessa forma não fazem mais que sua obrigação. $A$ ênfase nas punições assegura o cumprimento das obrigações. As recompensas são raras e predominantemente materiais ou salariais, sempre frias e impessoais.

- Sistema ll - Autoritário Benevolente: Nada mais é do que uma atenuação do primeiro sistema, mais condescendente e menos rígido. Suas principais características são:

Processo decisorial: centralizado na cúpula, permite uma pequena delegação nas decisões de caráter rotineiro e repetitivo, sempre baseado em rotinas e prescrições simples sujeitas a posterior aprovação. Prevalece a centralização.

Sistema de comunicações: relativamente precário, prevalecendo comunicações verticais e descendentes, embora a cúpula se oriente em comunicações ascendentes vindas dos 
escalões mais baixos, como retroação de suas decisões.

Relacionamento interpessoal: a organização informal é tolerada e ainda considerada uma ameaça aos interesses e objetivos da empresa. A interação humana é permitida.

Sistema de recompensas e punições: a ênfase nas punições e medidas disciplinares é mais branda. As recompensas materiais e salariais mais frequentes, aparecendo, também, as do tipo simbólico ou social.

Sistema III-Consultivo: Representa um abrandamento da arbitrariedade organizacional, mais participativo que os anteriores. As principais características são:

Processo decisorial: é participativo e consultivo, ou seja, as decisões específicas são delegadas aos diversos níveis hierárquicos e tomados com base nas políticas e diretrizes institucionais, verdadeiros balizadores construídos a partir da participação de todos os níveis.

Sistema de comunicações: prevê orientação vertical ampla, bem como comunicações laterais entre os pares. Surgem sistemas internos de comunicação.

Relacionamento interpessoal: a empresa facilita a organização informal sadia e positiva, privilegiando o relacionamento humano e a confiança.

Sistema de recompensas e punições: destaque para recompensas materiais e simbólicas. Punições e castigos são eventuais.

Sistema IV - Participativo: é o sistema democrático por excelência, totalmente aberto. Suas principais características são:

Processo decisorial: o consenso é a principal característica. As decisões são delegadas aos níveis inferiores com políticas e diretrizes definidas pela alta administração, que passa a assumir em ocasiões de emergência, sempre, porém, com a ratificação dos diversos grupos envolvidos.

Sistema de comunicações: a informação flui em todos os sentidos gerando flexibilidade, eficiência e eficácia.

Relacionamento interpessoal: participação e envolvimento grupal intenso gerando confiança mútua e trabalho em equipe, de maneira que todos se sintam responsáveis pelo que decidem e fazem.

Sistema de recompensas e punições: ênfase nas recompensas simbólicas e sociais, embora ainda existam as salariais e materiais. As punições são raras e definidas pelos grupos envolvidos.

Likert concluiu que os sistemas administrativos não são discretos nem descontínuos, permitindo variações intermediárias. Assim, mesmo que possam haver variações entre departamentos de uma mesma organização, de um modo geral, quanto mais próxima do Sistema I tanto mais tradicional, fechada, burocratizada, impessoal e autocrática é a administração. Por outro lado, quanto mais próxima do Sistema IV tanto mais a administração é aberta, orgânica, participativa e democrática. A recomendação do autor, então, é que as empresas procurem passar dos sistemas I e II, que são os menos participativos, para os sistemas III e IV, nos quais, por força de maior participação, haverá um clima de maior satisfação das pessoas e consequentemente de mais elevados padrões de resultados.

O autor também avaliou o comportamento humano na organização e percebeu três tipos de variáveis: causais, intervenientes e resultantes. Nas causais encontram-se o estilo de administração, as estratégias, a estrutura organizacional e a tecnologia empregada. Nas intervenientes estão as atitudes, motivações e percepções dos membros do grupo. Já nas resultantes figuram a produtividade, os lucros e os custos. Assim, as variáveis causais provocam estímulos que atuam nos indivíduos (variáveis intervenientes) gerando certas respostas (variáveis de resultado). Cada liderança dará ênfase a um tipo de variável negligenciando e gerando dificuldade nas demais, cabendo ao administrador a percepção sobre qual tipo de variável terá a sua preferência. 


\section{Metodologia}

O presente artigo buscou atingir seus objetivos através das técnicas apresentadas a seguir.

Como explicitam Diehl e Tatim(2004), trata-se de uma pesquisa quantitativa, pois como o próprio termo diz, lança mão da quantificação como forma de resposta ao questionamento central que se dedica, tanto na coleta quanto no tratamento das informações obtidas. Segundo os mesmo autores, trata-se de um estudo descritivo pois relaciona as características de determinada população, estabelecendo relações entre variáveis, gerando um resultado chamado de diagnóstico, o qual analisa o ambiente organizacional, revelando a situação específica do público estudado. Os mesmos autores ainda afirmam que se trata de um levantamento, uma vez que faz questionamento direto ao público envolvido, cujo comportamento se deseja conhecer.

Dessa forma, foi realizado um levantamento bibliográfico do tema central para que fossem alicerçadas as bases do estudo aqui discutido. Mais tarde, após uma análise documental que analisou diversos relatórios da empresa estudada, elaborou-se um formulário de pesquisa contendo 21 perguntas fechadas, dividas em duas partes. A primeira buscou identificar o público alvo estudado, trazendo características pessoais dos gerentes e aspectos das agências por eles administradas. A segundo parte identificou os aspectos da liderança por eles adotada, questionando os administradores quanto ao processo decisorial que se utilizam, aos sistemas de comunicação seus e de sua equipe, ao relacionamento interpessoal entre os funcionários da filial e aos sistemas de recompensas e punição existentes em suas agências bancárias. Cabe ressaltar que todos estes aspectos levam em conta a pessoa central do líder e a relação deste com os demais colaboradores.

Após a realização de um teste, com posterior correção, o formulário foi enviado, via malote interno, às 329 agências bancárias que a instituição estudada mantém no Estado do Rio Grande do Sul, sendo que destes, 212 retornaram aos pesquisadores.

Por fim, utilizando-se das técnicas estatísticas de frequência descritas por Apollinário(2006), relacionando as variáveis citadas anteriormente, foram alcançados os resultados que ora são descritos.

\section{Discussão dos resultados}

Do total de 329 formulários enviados, obteve-se, como já citado, o retorno de 212 deles, ou seja, um total de $65 \%$ de retorno, o que garante uma pesquisa com alta taxa de certeza.

A primeira parte do formulário buscou traçar o perfil dos respondentes no que tange às características pessoais, tais como sexo, idade, formação acadêmica e tempo em que trabalha na instituição, além de características das agências bancárias onde estão inseridos, incluindo $\mathrm{o}$ atingimento das metas propostas.

Assim, num primeiro momento, cabe destacar o perfil dos respondentes.

No que tange ao sexo, a pesquisa comprova o que pode facilmente ser observado na prática do ramo bancário, $93,87 \%$ dos respondentes são homens, aparecendo apenas $6,13 \%$ de mulheres. Cabe ressaltar que diversos programas estão sendo desenvolvidos pela diretoria buscando a igualdade de gêneros, porém todos têm um tempo muito grande de eficácia, já que também é muito difícil encontrar-se mulheres candidatas aos cargos de gerência de agência.

Quanto à idade, a maioria $(80,66 \%)$ é compostas de pessoas acima de 41 anos, já que $50,47 \%$ estão na faixa dos 40 anos e $30,19 \%$ estão acima desta faixa. Na faixa dos 30 anos aparecem $17,45 \%$ dos respondentes e apenas $1,89 \%$ está na faixa dos vinte anos.

Unida à idade vem a questão tempo em que trabalham na instituição. Aqui $61,32 \%$ estão 
na casa há mais de 25 anos e $26,89 \%$ há mais de vinte anos, restando apenas $11,79 \%$ dos respondentes com menos de duas décadas de dedicação ao banco estudado. Esta informação leva a crer que a maioria absoluta dos gerentes aqui pesquisados tem fortemente internalizadas as políticas e diretrizes da instituição em que trabalham. Fazendo-se uma análise conjunta dos dados de idade e tempo de casa, conclui-se que somente após certo período de tempo de dedicação e maturidade alcançada é que os funcionários ascendem ao nível hierárquico pesquisado, ou seja, a instituição tem, em suas políticas de gestão de pessoas, um perfil básico de gerente aqui externado, especialmente em termos de idade e tempo dedicado ao banco pesquisado.

Outro item diz respeito à formação acadêmica dos gerentes. A conclusão é que $44,69 \%$ deles são graduados em administração, seguidos de 22,12\% em ciências contábeis, $13,72 \%$ em direito e $8,85 \%$ em economia. Chama a atenção o percentual de $6,60 \%$ dos respondentes com duas graduações e, também, o de 9,43\% com graduações em áreas nada afins ao serviço bancário, tais como engenharias, arquitetura, agronomia ou zootecnia, por exemplo. Aqui cabe ressaltar outra política da instituição que privilegia os funcionários formados em administração e áreas afins, todas muito ligadas ao dia-a-dia de trabalho.

No instante subsequente, o formulário buscou informações acerca das características das agências dos entrevistados, tais como, tamanho, região de localização, quantidade de funcionários e de gerentes de nível médio subordinados.

Em termos de região de localização, os respondentes são procedentes, em sua maioria, do interior do Estado, num total de $73,12 \%$. Destes, pode-se considerar que 38,21\% estão em locais com características de latifúndios (16,51\% na região de Santa Maria, $13,21 \%$ na de Santa Rosa e 8,49\% na de Pelotas), enquanto que $34,91 \%$ em regiões de minifúndios $(19,34 \%$ na região de Passo Fundo e $15,57 \%$ na de Caxias do Sul). Os $26,88 \%$ restantes se dividem nas regiões essencialmente urbanas do Estado: $10,85 \%$ na região de Novo Hamburgo e o percentual de $8,02 \%$ nas regiões de Porto Alegre e de Canoas.

$\mathrm{Na}$ instituição estudada, as agências são divididas em cinco níveis hierárquicos distintos, de acordo com o volume de negócios que detém, variando de um, para as maiores, até cinco, para as menores. Neste ponto, os respondentes são em sua maioria, num total de $46,70 \%$ pertencentes a agências nível três, consideradas de médio porte; seguidos de $29,24 \%$ nas de nível quatro e cinco, de pequeno porte, e $24,06 \%$ nas de nível um e dois, de grande porte.

No que tange à quantidade de funcionários, as agências com até quinze colaboradores fechou o percentual de $62,74 \%$ do total (sendo $30,66 \%$ para até 7 e $32,08 \%$ para de 8 a 15 funcionários), seguidas de $21,70 \%$ entre 16 e 25 pessoas e 15,57\% para mais de 25 pessoas.

$\mathrm{Na}$ questão de quantidade de gerentes subordinados, a maioria dos respondentes, $34,43 \%$ do total, tem apenas um e $24,53 \%$ têm mais de cinco gerentes de nível médio ligados a si diretamente. Completando os percentuais aparece que $11,79 \%$ têm dois, $10,85 \%$ têm cinco, $9,91 \%$ têm quatro e $8,49 \%$ têm três gerentes subordinados. Analisando conjuntamente o perfil das agências, pode-se concluir que as de maior porte estão mais bem dotadas de funcionários, sejam gerentes ou não, enquanto que as menores, mesmo sendo maioria, têm carência de pessoas, especialmente comissionadas com alto grau de compromisso com a empresa.

Numa última questão, isolada das demais, foi solicitado aos respondentes que informassem dados relativos aos cumprimentos de metas por sua agência, levando em consideração o programa interno desenvolvido pela própria instituição. Cabe ressaltar que as agências são por este modelo, distribuídas em quatro níveis que denotam classificação: inicial, bronze, prata e ouro, sendo este último o melhor da escala. Assim, 50,94\% ficaram na etapa ouro, $33,96 \%$ na bronze e $13,68 \%$ na prata, seguidas de $1,42 \%$ na inicial. 
A segunda parte do formulário de pesquisa buscou identificar as características gerais da liderança exercida pelo gerente, segundo a sua própria opinião. As questões foram subdivididas em quatro grupos, de acordo com as variáveis estudadas: processo decisorial, sistema de comunicações, relações interpessoais e sistema de recompensas e punições, sempre realizadas na forma de uma afirmação prática do dia-a-dia do entrevistado. As respostas variavam numa escala de zero a oito, sendo que o ponto inicial correspondia a nunca realização da afirmativa e o ponto final a sempre realização. Esta segunda parte tinha por fim identificar que Sistema de Administração é o mais usado pelos respondentes.

$\mathrm{Na}$ primeira variável, chamada de processo decisorial, foi testado, através de duas questões, o quanto as decisões são tomadas em colegiado e chegou-se a conclusão de que $65,57 \%$ dos entrevistados adotam o Sistema Participativo, ficando para 33,49\% o Sistema Consultivo e apenas $0,94 \%$ o Sistema Autoritário Coercitivo.

No item sistema de comunicações, que mede a maneira como as informações fluem na organização, um grupo de quatro questões definiu que $55,19 \%$ dos entrevistados adotam o Sistema Participativo; 37,74\% o Consultivo e 7,07\% o Autoritário Benevolente.

No grupo que mediu as relações interpessoais, buscando entender a informalidade da organização, um grupo de quatro perguntas definiu que o percentual de $66,51 \%$ adota o Sistema Participativo, enquanto que $30,66 \%$ o Consultivo e $2,83 \%$ o Autoritário Benevolente.

Por fim, uma dupla de questões sobre o sistema de recompensas e punições apresentou que $62,03 \%$ adotam o Sistema Participativo; $34,43 \%$ o Consultivo e 3,54\% o Autoritário Benevolente.

Tratando os dados de uma forma geral, pode-se concluir que $66,51 \%$ dos entrevistados adotam o Sistema Participativo em suas práticas diárias de administração, enquanto que $33,02 \%$ são adeptos ao Sistema Consultivo, restando apenas um administrador (ou 0,47\%) que ainda utiliza do Sistema Autoritário Benevolente.

Considerando o nível das agências, encontramos uma igualdade de proporções aos níveis gerais quando citadas as agências de nível 1 e 3 , o que leva a concluir que nas grandes e médias dois terços dos administradores utilizam o Sistema Participativo. Nas de nível 4, o índice de participativos aumenta para 78,05\%, enquanto que nas de nível 2 e 5 ocorre praticamente um empate técnico, no qual $55 \%$ são participativos e $45 \%$ são Consultivos.

Considerando a quantidade de funcionários existentes nas dependências, os níveis não sofrem grandes nuances quando comparados com os gerais, sugerindo que independentemente do número de funcionários, os administradores utilizam os mesmos sistemas.

Quando levado em conta o resultado da agência, aquelas com pontuações de nível bronze e ouro se equivalem aos níveis gerais de sistemas utilizados, havendo destaque para as que chegaram ao nível prata, no qual $79,31 \%$ dos administradores declaram-se participativos e apenas $20,69 \%$ consultivos, diferentemente da média geral já exposta.

Por fim, quando levada em consideração a região onde a agência está instalada, o grande destaque foi à área de Pelotas onde 16 dos 18 respondentes, ou seja 88,89\%; adotam o Sistema Participativo, seguido de Passo Fundo com 73,17\% e Porto Alegre com 70,59\% dos administradores. Ressalta-se, também, a região de Novo Hamburgo com $54,55 \%$ de participativos e $40,91 \%$ de consultivos. Nas demais, quais sejam, Canoas, Caxias do Sul, Santa Maria a Santa Rosa os níveis gerais se mantiveram. Estes dados trazem a ideia de que independe da região geográfica e do público atendido o método administrativo utilizado, já que áreas urbanas como Novo Hamburgo, Porto Alegre e Canoas têm percentuais inconstantes entre si, exatamente da mesma forma que as demais regiões do interior do Estado do Rio Grande do Sul. 


\section{Considerações finais}

Tomando por base os dados apresentados neste artigo, pode-se concluir que os gerentes da instituição analisada acompanham as tendências mundiais das técnicas administrativas, as quais consideram de suma importância a participação das pessoas em todas as fases do processo produtivo, desde a sua concepção até a finalização e posterior revisão. A pesquisa demonstrou que os administradores conseguem obter melhores resultados se considerarem a atuação de pessoas nos diversos procedimentos, independentemente da região onde estiverem inseridos, do público a ser atendido, do tamanho da filial e até mesmo da quantidade de pessoas que forma a equipe.

Em consonância com antigas e atuais teorias administrativas, a pesquisa verificou que a maioria absoluta dos gerentes utiliza-se do método participativo de liderar, observando quatro aspectos importantes. O primeiro deles diz respeito aos sistemas de recompensas e punições e verificou que as penalizações por erros são pouco utilizadas, enquanto que a valorização pelos acertos é largamente empregada. Num segundo instante, observou-se que a comunicação em todos os sentidos flui livremente nas filiais analisadas, fazendo com que gerentes e subordinados compartilhem dados importantes ao seu dia-a-dia de trabalho. Já uma terceira característica concluiu que nas agências estudadas existe um clima de confiança mútua e envolvimento de todos em prol dos objetivos a serem atingidos. Um último aspecto observado, o processo de tomada de decisão resume muito bem as atitudes dos líderes das agências pesquisadas, pois tanto as políticas a serem seguidas internamente, quanto às decisões em si são tomadas em conjunto com os funcionários, e não somente na cúpula.

Concluindo, o estudo comprova a real eficácia das teorias relatadas por Rensis Likert em seus diversos escritos literários, trazendo a certeza de que as pessoas são importantes recursos nas organizações, devendo ser respeitadas como seres humanos que são, cada um com valores, necessidades, motivações, aspirações próprias. Cabe, assim, ao administrador verificar que atitude deve ser tomada em razão de seu grupo de funcionários, estando ciente de que quanto mais participativo for o estilo de liderança adotado, maior será a probabilidade dele e sua equipe atingirem níveis ótimos de sucesso frente aos desafios do mercado contemporâneo globalizado. 


\section{Referências Bibliográficas}

APPOLINÁRIO, Fábio. Metodologia da ciência: filosofia e prática da pesquisa. São Paulo: Pioneira Thomson Learning, 2006. 1994.

BERGAMINI, Cecília Whitaker. Liderança: administração do sentido. São Paulo: Atlas, O líder eficaz. São Paulo: Atlas, 2006.

BIRCK, Luís Fernando. O líder profissional: comportamentos e atitudes para ter uma equipe entusiasmada. Canoas: Tecnicópias, 2006.

BOM SUCESSO, Edina de Paula. Relações interpessoais e qualidade de vida no trabalho. Rio de Janeiro: Qualitymark, 2002. 1999.

CHIAVENATO, Idalberto. Teoria geral da administração. 6 ed. Rio de Janeiro: Campus, Recursos humanos. Ed. Compacta, 6 ed. São Paulo: Atlas, 2000.

. Gerenciando pessoas: como transformar os gerentes em gestores de pessoas. 4 ed. São Paulo: Prentice Hall, 2002.

Gestão de pessoas: o novo papel dos recursos humanos nas organizações. 3 ed. Rio de Janeiro: Elsevier, 2008.

COSTA, Eliezer Arantes da. Gestão estratégica. São Paulo: Saraiva, 2003.

CRIVELARO, Rafael; TAKAMORI, Jorge Yukio. Dinâmica das relações interpessoais. Campinas: Editora Alínea, 2006.

DIEHL, Astor Antônio; TATIM, Denise Carvalho. Pesquisa em ciências sociais aplicadas: métodos e técnicas. São Paulo: Prentice Hall, 2004.

GRACIOSO, Francisco. Marketing estratégico: planejamento estratégico orientado para o mercado. 4 ed. São Paulo: Atlas, 2001.

HUNTER, James C. Como se tornar um líder servidor. Tradução de A. B. Pinheiro de Lemos. Rio de Janeiro: Sextante, 2006.

LIKERT, Rensis. A organização humana. Tradução de Márcio Cotrim. São Paulo: Atlas, 1975.

Novos padrões de administração. Tradução de Albertino Pinheiro Júnior e Ernesto D’Orsi. 2 ed. São Paulo: Pioneira, 1979.

LIKERT, Rensis; LIKERT, Jane Gibson. Administração de conflitos: novas abordagens. Tradução de Joaquim O. Pires da Silva. Revisão técnica de Eunice Lacava Kwasnicka. São Paulo: McGraw-Hill do Brasil, 1979.

WHITTINGTON, Richard. O que é estratégia. Tradução de Maria Lúcia G. L. Rosa e Martha Malvezzi Leal. Revisão técnica de Flávio Carvalho de Vasconcelos. São Paulo: Pioneira Thomson Learning, 2002. 